\title{
1 ATRIAL FIBRILLATION AND STROKE: A PRACTICAL GUIDE
}

2

3 4

5

6

7

8

9

10

11

12
Jonathan G Best ${ }^{1}$, Robert Bell ${ }^{2}$, Mohammed Haque ${ }^{3}$, Arvind Chandratheva ${ }^{3}$, David J Werring ${ }^{1,3}$

Corresponding author: Professor David Werring

Stroke Research Centre, University College London

$1^{\text {st }}$ Floor Russell Square House

$10-12$ Russell Square

London WC1B 5EH

Email: d.werring@ucl.ac.uk

Tel: 02031087493

Author affiliations:

1. Stroke Research Centre, University College London, London, UK

2. Institute of Cardiovascular Science, University College London, UK

3. Comprehensive Stroke Service, University College London Hospitals NHS Foundation Trust, London, UK

Word Count: 7006 
2 Neurologists and stroke physicians will be familiar with atrial fibrillation as a major cause of ischaemic 3 stroke, and the role of anticoagulation in preventing cardioembolic stroke. However, making decisions 4 about anticoagulation for individual patients remains a difficult area of clinical practice, in which the serious risks of ischaemic stroke and major bleeding, particularly intracranial haemorrhage, must be carefully balanced. Atrial fibrillation is an interdisciplinary condition, in which collaboration with colleagues in cardiology and haematology is essential. Recent advances in the field, most notably the now-widespread availability of direct oral anticoagulants, have brought opportunities to improve stroke care while posing new challenges. This article gives an overview of the contemporary diagnosis and management of atrial fibrillation, and the associated evidence base. Where uncertainty exists, we describe our own approach to these areas, while highlighting ongoing research which is likely to guide future practice. 


\section{INTRODUCTION}

Atrial fibrillation (AF) affects $2 \%$ of the UK population over 45 years old, and $4 \%$ of those over 65 [1]. It causes at least one-fifth of ischaemic strokes [2], and is one of the strongest individual stroke risk factors [3]. Most AF patients presenting to a neurologist will do so following an ischaemic stroke or TIA, but AF may also be found incidentally. The mainstay of stroke prevention in AF is anticoagulation, which is highly effective in preventing disabling ischaemic cardioembolic stroke, but can cause serious complications, most notably intracranial haemorrhage, which is unpredictable and often fatal or disabling. Treatment decisions in AF are therefore often complex and associated with important risks that are difficult to quantify. Indeed, balancing treatments to reduce ischaemic (vaso-occlusive) events while minimising the risk of intracranial bleeding is a central challenge of stroke medicine. Here, we aim to provide an overview and practical approach to the common issues likely to be encountered by neurologists in relation to atrial fibrillation, while highlighting some important uncertainties.

\section{ATRIAL FIBRILLATION AS A RISK FACTOR FOR ISCHAEMIC STROKE}

The first description of atrial thromboembolism came, perhaps surprisingly, from a neurologist: in 1875, William Gowers described simultaneous emboli in the brain and retina, spleen and kidneys, concluding that they had all originated in the left atrial appendage, which contained clots [4]. In the early $20^{\text {th }}$ century autopsy studies linked mitral stenosis, AF and intracardiac thrombus formation, and so identified the contribution of AF to stroke risk [5]. The connection between "non-valvular" AF and stroke was then consolidated by Miller Fisher and Adams in 1951 [6]. The risk was quantified by Wolf and colleagues in 1978, using epidemiological data from the Framingham study: valvular and nonvalvular AF increased ischaemic stroke risk 17-fold and five-fold respectively overall [7]. Much effort has since aimed to estimate ischaemic stroke risk in individual patients, producing the risk scoring systems which are the mainstay of current guidelines.

\section{Paroxysmal, persistent, and permanent AF}

An initial consideration in estimating ischaemic stroke risk is whether all types of AF - paroxysmal, persistent, and permanent - are equivalent. No current national or international guideline makes a distinction [8-10], based largely on observational longitudinal data from the Stroke Prevention in Atrial Fibrillation studies in the 1980s and 90s, which showed no difference in annual ischaemic stroke rate in aspirin-treated patients in paroxysmal versus persistent or permanent AF (3.2\% vs. 3.3\%) [11]. Conflictingly, a more recent retrospective analysis of patients enrolled into the ACTIVE-A and AVERROES studies receiving aspirin monotherapy suggests that persistent and permanent AF might carry a higher risk than paroxysmal AF (3.0\%, 4.2\%, and 2.1\%/year, respectively) [12]. These results 
might be more applicable to contemporary practice, given advances in the management of other cardiovascular risk factors. However, in practice, a quarter of patients with paroxysmal AF will progress to persistent or permanent AF within five years, and a third within ten years [13]. In our view it is therefore reasonable to treat paroxysmal, persistent, and permanent AF in the same way.

\section{Risk scores: CHADS2 and CHA2DS2VASc}

The first widely-adopted AF stroke risk score was the CHADS2 score (table 1), which included risk factors identified by the Atrial Fibrillation Investigators (AFI) [14] and the Stroke Prevention and Atrial Fibrillation (SPAF) investigators [15], and was validated in an independent cohort of 1,733 Medicare beneficiaries [16]. Limitations included the exclusion of patients under 65, limiting widespread applicability, and the inclusion of a low proportion of high-risk (CHADS2 >4) patients, giving rise to wide confidence intervals for ischaemic stroke risk in higher-scoring patients (table 2). Importantly, around a quarter of patients in the validation cohort had an "intermediate risk" CHADS2 score of 1, a proportion that increased to $60 \%$ in subsequent studies [17]. This is problematic because in this large patient population the treating physician would need to make a judgement between doing nothing, giving aspirin (no longer advised under European Society of Cardiology guidelines) or recommending anticoagulation.

Table 1: CHADS2 and CHA2DS2VASc risk scores

\begin{tabular}{|l|c|l|c|}
\hline \multicolumn{2}{|l|}{ CHADS2 } & CHA2DS2VASc & Score \\
\hline Risk factor & Score & Risk factor & 1 \\
\hline $\begin{array}{l}\text { Congestive } \\
\text { heart failure }\end{array}$ & 1 & Congestive heart failure & \\
\hline Hypertension & 1 & Hypertension & 1 \\
\hline Age $\geq 75$ & 1 & Age $\geq 75$ & 2 \\
\hline Diabetes & 1 & Diabetes & 1 \\
\hline Stroke/TIA & 2 & Stroke/TIA & 1 \\
\hline & & Vascular (MI, PAD, aortic plaque) & 1 \\
\cline { 2 - 4 } & & Age $\geq 65$ (<75) & 1 \\
\cline { 2 - 4 } & & Sex category (female) & 2 \\
\hline
\end{tabular}

Score <1: Low risk; 1: intermediate risk; >1 high risk*

\footnotetext{
* Note that in ESC 2016 guidelines that female gender alone does not score 1 unless in presence of an additional risk factor
} 


\begin{tabular}{|c|c|c|c|cc|}
\hline Risk score & $\begin{array}{c}\text { Number of } \\
\text { patients } \\
(\mathbf{n = 1 , 7 3 3 )}\end{array}$ & $\begin{array}{c}\text { Number as } \\
\text { percentage of } \\
\text { cohort }\end{array}$ & $\begin{array}{c}\text { Number of } \\
\text { strokes } \\
(\mathbf{n}=94)\end{array}$ & $\begin{array}{c}\text { Adjusted annual } \\
\text { stroke rate (95\% Cl) }\end{array}$ \\
\hline 0 & 120 & 6.9 & 2 & $1.9(1.2-3.0)$ & \\
\hline 1 & 463 & 26.7 & 17 & $2.8(2.0-3.8)$ & 5 \\
\hline 2 & 523 & 30.2 & 23 & $4.0(3.1-5.1)$ & 6 \\
\hline 3 & 337 & 19.4 & 25 & $5.9(4.6-7.3)$ & \\
\hline 4 & 220 & 12.7 & 19 & $8.5(6.3-11.1)$ & 7 \\
\hline 5 & 65 & 3.8 & 6 & $12.5(8.2-17.5)$ & 8 \\
\hline 6 & 5 & 0.3 & 2 & $18.2(10.5-27.4)$ & 9 \\
\hline
\end{tabular}

The CHA2DS2VASc system was developed in response, by including additional risk factors and a lower age threshold of 65 years while further weighting ages over 75 years (table 1) [17]. Validated on the Euro Heart Survey on AF population in 1,084 patients not taking anticoagulants at baseline, the CHA2DS2VASc low-risk category had a very low incidence of thromboembolic events (none in the initial validation cohort, table 3), and the number of patients categorised as being at intermediate risk (14.9\%) was lower than with CHADS2 (table 3). There remain limitations of this revised score: a number of important ischaemic stroke risk factors are not included - notably left atrial remodelling from any aetiology (detectable on echocardiography), chronic kidney disease (particularly those with CKD 3B or greater $\left(\right.$ eGFR $\left.<45 \mathrm{ml} / \mathrm{min} / 1.73 \mathrm{~m}^{2}\right)$ ), obstructive sleep apnoea, circulating cardiac biomarkers (review [18]), or brain biomarkers of cerebrovascular disease [19]. Scoring systems that incorporate one or more of these factors have been developed and are in the process of validation. For example, the ABC score combines age, cardiac biomarkers (NT-proBNP and Troponin I), and clinical history of stroke or TIA, outperforming CHA2DS2VASc in its derivation and external validation cohorts, with c-statistics of 0.68 and 0.66 vs. 0.62 and 0.58 respectively [20]. However, whether such scores offer a significant advantage in clinical practice over the simple and cheap CHA2DS2VASc score remains to be determined. 


\begin{tabular}{|c|c|c|c|c|c|}
\hline Risk score & $\begin{array}{c}\text { Number of } \\
\text { patients } \\
(\mathbf{n}=\mathbf{1 , 0 8 4})\end{array}$ & $\begin{array}{c}\text { Number as } \\
\text { percentage } \\
\text { of cohort }\end{array}$ & $\begin{array}{c}\text { Number of } \\
\text { strokes } \\
(\mathbf{n}=\mathbf{2 5})\end{array}$ & $\begin{array}{c}\text { Annual stroke } \\
\text { rate } \\
(\mathbf{9 5 \%} \mathbf{C l})\end{array}$ & $\begin{array}{c}\text { Annual stroke } \\
\text { rate adjusted } \\
\text { for aspirin use }\end{array}$ \\
\hline 0 & 103 & 9.5 & 0 & $0(0-0)$ & 0 \\
\hline 1 & 162 & 14.9 & 1 & $0.6(0.0-3.4)$ & 0.7 \\
\hline 2 & 184 & 17.0 & 3 & $1.6(0.3-4.7)$ & 1.9 \\
\hline 3 & 203 & 18.7 & 8 & $3.9(1.7-7.6)$ & 4.7 \\
\hline 4 & 208 & 19.2 & 4 & $1.9(0.5-4.9)$ & 2.3 \\
\hline 5 & 95 & 8.8 & 3 & $3.2(0.7-9.0)$ & 3.9 \\
\hline 6 & 57 & 5.3 & 2 & $3.6(0.4-12.3)$ & 4.5 \\
\hline 7 & 25 & 2.3 & 2 & $8.0(1.0-26.0)$ & 10.1 \\
\hline 8 & 9 & 0.8 & 1 & $11.1(0.3-48.3)$ & 14.2 \\
\hline 9 & 1 & 0.1 & 1 & $100(2.5-100)$ & 100 \\
\hline
\end{tabular}

2

Risk scores: more than stroke risk?

An interesting point to note is that the CHADS and CHA2DS2VASc scores are essentially summaries of cardiovascular risk factors that portend endothelial and myocardial dysfunction, and so do not only predict ischaemic stroke risk. Even in patients without AF, both scores correlate with measures of general vascular dysfunction and perform moderately well in predicting ischaemic stroke, myocardial infarction and cardiovascular death [21]. Moreover, in patients admitted with an acute coronary syndrome, the CHADS2 and CHA2DS2VASC scores also predict ischaemic stroke independently of an antecedent diagnosis of AF [22]. Both scores also predict new onset of AF, with c-statistics of 0.72 and 0.74 respectively [23]. Therefore, in those with cryptogenic stroke, a high CHA2DS2VASc score should perhaps prompt a more aggressive rhythm monitoring strategy in those patients in whom initial rhythm monitoring has not made an AF diagnosis.

\section{DIAGNOSIS OF AF AFTER STROKE}

In the UK, $15-20 \%$ of acute ischaemic stroke patients have known atrial fibrillation at the time of stroke $[24,25]$. Standard guideline-based investigations for AF in the remainder, if potentially eligible for anticoagulation, would comprise a routine ECG on admission, inpatient telemetry lasting $12-24 \mathrm{hrs}$, and, in the absence of a definite alternative mechanism, further outpatient monitoring, usually for 17 days [26-28]. A further $\sim 20 \%$ of patients will be diagnosed with AF by this approach [2]. Three major 
1 randomised controlled trials have examined what further monitoring should be undertaken in patients

2 with cryptogenic stroke (i.e. those with no alternative cause found after standard investigations,

3 including imaging of the extracranial arteries): CRYSTAL-AF, EMBRACE, and FIND AF RANDOMISED [29-31].

4 The results, summarised in Table 4, showed significantly higher detection rates with more intensive 5 rhythm monitoring strategies than with standard care. Higher use of oral anticoagulation resulted,

6 though these studies were not powered to show reduced recurrent stroke risk. In CRYSTAL-AF, the 7 detection rate continued to rise past one year, reaching $30 \%$ at 3 years [32]. Although this might 8 partially represent incident AF unrelated to the original stroke, this finding would still generally justify 9 anticoagulation in an ischaemic stroke patient. 

detection in the intervention (I) and control (C) arms of the studies.

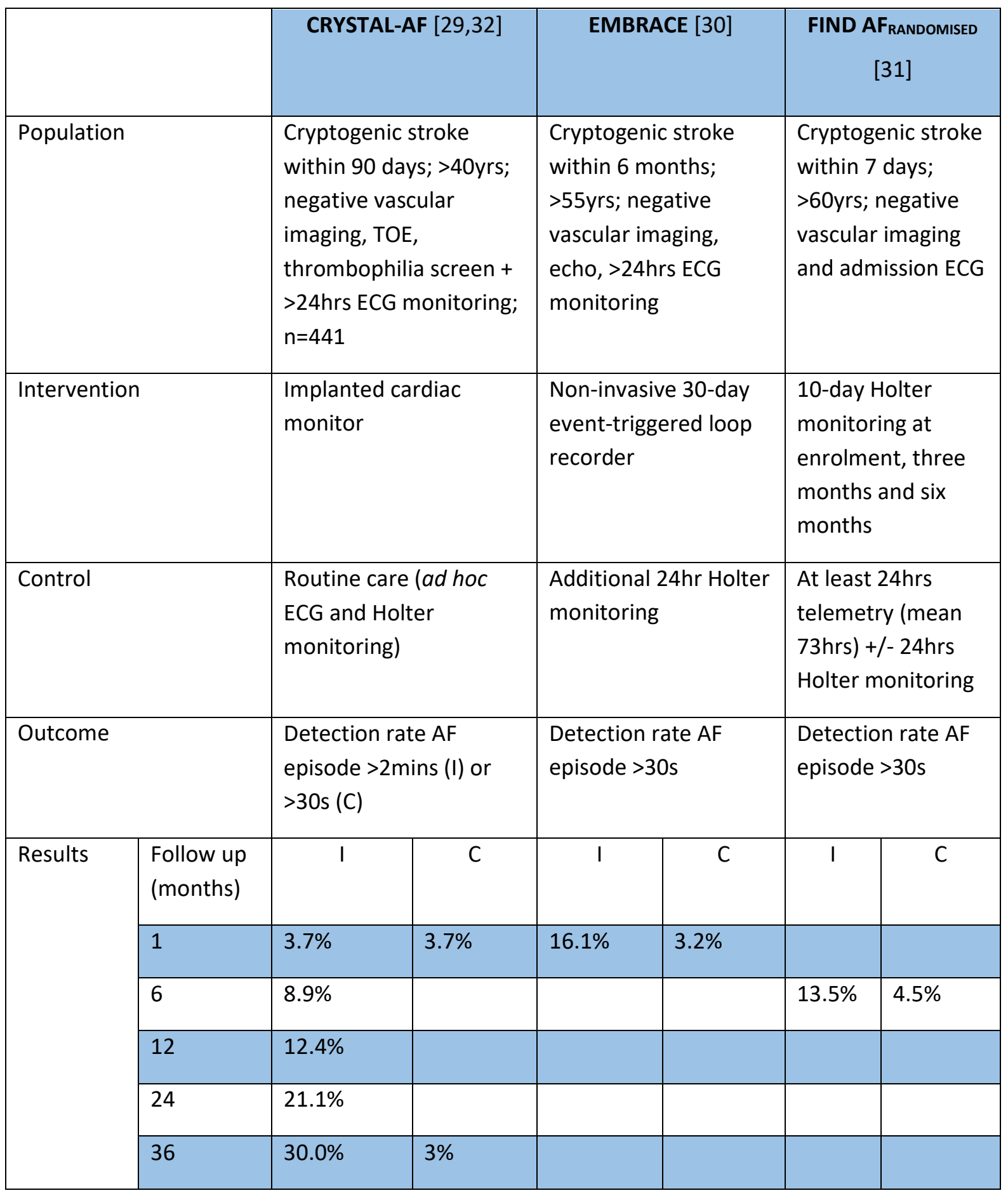


Risk factors and biomarkers of AF could theoretically help select patients for prolonged monitoring. However, many patient-related risk factors for AF, such as age and hypertension, are poorlydiscriminating, also being risk factors for atherosclerosis [33]. Heart failure and mitral stenosis might be more specific [34], and the recently-developed HAVOC risk score, which weights congestive heart failure heavily, has shown potential for triaging cryptogenic stroke patients into low, medium and high-risk categories for AF detection [35]. ECG biomarkers including PR prolongation and atrial premature beat count are also being developed $[36,37]$.

Clinical and radiological features might also help identify patients likely to have AF. Large cardiac fibrinrich thrombi tend to travel in medium calibre high-flow vessels, leading to proximal arterial occlusion and a large infarct, or fragmentation and distal embolization into terminal cortical branches. Consequently, the features of cardioembolic stroke include higher clinical severity, more cortical symptoms and signs, and certain radiological patterns (figure 1), including whole-territory infarction, wedge-shaped infarcts extending into the cortex, striatocapsular infarction (from transient M1 occlusion), isolated posterior cerebral artery infarction causing hemianopia, scattered distal infarcts within an arterial territory or external borderzone, and multi-territory bihemispheric or anterior and posterior circulation infarcts [38]. Haemorrhagic transformation has also been suggested to be characteristic of cardiac embolism, since cardiac, "red" (fibrin-rich) thrombi are more liable to reperfuse and consequently have associated haemorrhage within the infarct. However, none of these findings are wholly reliable: even small subcortical infarction has been described in the presence of a definite embolic mechanism [39], and a recent meta-analysis showed that the AF detection rate at seven days after ischaemic stroke is similar whether the stroke is classified clinico-radiologically as due to small or large vessel occlusion [40]. Importantly, high detection rates in the prolonged monitoring trials were obtained in relatively unselected cryptogenic stroke patients. Therefore, until a biomarkerbased approach is validated, we advocate prolonged monitoring in all cryptogenic stroke patients.

\section{Monitoring techniques}

The optimal techniques for ECG monitoring are uncertain, with a lack of head-to-head trials and recent rapid advances in device design. In most departments, first-line non-invasive AF detection remains via Holter monitoring, developed in 1962 and limited by relatively short recording duration, bulky design, an inability to use while showering, and delays in reporting. Newer hand-held patient-activated devices such as Kardia and Zenicor offer portability, cost-effectiveness and speed [41], but do not offer the continuous monitoring required to detect asymptomatic AF. Our preference is for newer patchmonitoring devices, such as ZIO, Bardy or e-Patch, or lead monitoring via R-test or Apoplex (table 5, 
1 figure 2). These devices allow continuous monitoring for longer durations, a lightweight water2 resistant design, easy application in clinic by a nurse or doctor, and email reporting within 72 hours. 
Table 5: ECG monitoring devices

\begin{tabular}{|c|c|c|c|c|c|c|}
\hline & \multicolumn{3}{|l|}{ Patch monitors } & \multicolumn{3}{|c|}{ Standard lead monitors } \\
\hline & CAM/Bardy & E-patch & $\mathrm{ZIO}$ & Apoplex & Holter & R-test \\
\hline \multicolumn{7}{|c|}{ Device characteristics } \\
\hline $\begin{array}{l}\text { Type of } \\
\text { device }\end{array}$ & $\begin{array}{l}\text { Lightweight } 2 \\
\text { lead patch* }\end{array}$ & $\begin{array}{l}\text { Lightweight } 2 \\
\text { lead patch }\end{array}$ & $\begin{array}{l}\text { Lightweight } \\
2 \text { lead patch }\end{array}$ & $\begin{array}{l}3 \text { lead Holter } \\
\text { monitor }\end{array}$ & $\begin{array}{l}\text { 3-5 Lead } \\
\text { monitor }\end{array}$ & $\begin{array}{l}\text { Single lead } \\
\text { monitor }\end{array}$ \\
\hline Showerproof & Y & Y & Y & $Y$ & $\mathrm{~N}$ & $Y$ \\
\hline $\begin{array}{l}\text { Device } \\
\text { applied in } \\
\text { clinic }\end{array}$ & Y & Y & Y & Y & $\mathrm{N}$ & Y \\
\hline $\begin{array}{l}\text { Additional } \\
\text { software } \\
\text { required to } \\
\text { allow upload } \\
\text { of data }\end{array}$ & $\mathrm{N}$ & Y & $\mathrm{N}$ & $Y$ & $N$ & Y \\
\hline $\begin{array}{l}\text { Recording } \\
\text { duration }\end{array}$ & 7 days & 5 days & 14 days & $\begin{array}{c}1-72 \\
\text { hours** }\end{array}$ & 1-7 days & 16-32 days \\
\hline $\begin{array}{l}\text { Time to } \\
\text { report }\end{array}$ & $<72 \mathrm{hrs}$ & $<72$ hours & 48-72hrs & $<24 \mathrm{hrs}$ & $\begin{array}{l}\text { Locally } \\
\text { dependent }\end{array}$ & 48hrs \\
\hline $\begin{array}{l}\text { Full report of } \\
\text { cardiac } \\
\text { rhythm } \\
\text { e.g. AF, SVT, } \\
\text { VT, ectopics, } \\
\text { pauses }\end{array}$ & Y & Y & $\begin{array}{l}\text { Y } \\
\text { excludes AF } \\
<30 \text { seconds }\end{array}$ & $\begin{array}{l}3 \text { outcomes, } \\
1=A F / P A F, \\
2=\text { increased } \\
\text { risk of } A F, 3 \\
=\text { no } \\
\text { evidence of } \\
\text { AF }\end{array}$ & Y & Y \\
\hline $\begin{array}{l}\text { What does } \\
\text { the patient } \\
\text { do with the } \\
\text { device? }\end{array}$ & $\begin{array}{l}\text { Device } \\
\text { posted by } \\
\text { patient to } \\
\text { manufacturer } \\
\text { for analysis } \\
\text { (freepost) }\end{array}$ & $\begin{array}{l}\text { Device } \\
\text { returned to } \\
\text { clinic and } \\
\text { data } \\
\text { uploaded for } \\
\text { analysis }\end{array}$ & $\begin{array}{l}\text { Device } \\
\text { posted by } \\
\text { patient to } \\
\text { manufacture } \\
r \text { for analysis } \\
\text { (freepost) }\end{array}$ & $\begin{array}{l}\text { Device } \\
\text { returned to } \\
\text { clinic and } \\
\text { data } \\
\text { uploaded for } \\
\text { analysis }\end{array}$ & $\begin{array}{l}\text { Device } \\
\text { returned to } \\
\text { clinic }\end{array}$ & $\begin{array}{l}\text { Device returned } \\
\text { to clinic and } \\
\text { data uploaded } \\
\text { for analysis }\end{array}$ \\
\hline $\begin{array}{l}\text { How is the } \\
\text { data } \\
\text { reported? }\end{array}$ & $\begin{array}{l}\text { Computer } \\
\text { algorithm } \\
\text { with cardiac } \\
\text { physiologist } \\
\text { review }\end{array}$ & $\begin{array}{l}\text { Computer } \\
\text { algorithm } \\
\text { with cardiac } \\
\text { physiologist } \\
\text { review }\end{array}$ & $\begin{array}{l}\text { Computer } \\
\text { algorithm } \\
\text { with cardiac } \\
\text { physiologist } \\
\text { review }\end{array}$ & $\begin{array}{l}\text { Computer } \\
\text { algorithm }\end{array}$ & $\begin{array}{l}\text { Cardiac } \\
\text { physiologist } \\
\text { with } \\
\text { cardiologist } \\
\text { review }\end{array}$ & $\begin{array}{l}\text { Computer } \\
\text { algorithm with } \\
\text { cardiac } \\
\text { physiologist } \\
\text { review }\end{array}$ \\
\hline $\begin{array}{l}\text { Results } \\
\text { reporting }\end{array}$ & Email report & $\begin{array}{l}\text { Email report } \\
\text { Option for } \\
\text { data to be } \\
\text { reviewed } \\
\text { locally }\end{array}$ & Online portal & Email report & $\begin{array}{l}\text { Local } \\
\text { arrangement } \\
\text { s for } \\
\text { feedback of } \\
\text { results }\end{array}$ & $\begin{array}{l}\text { Email report } \\
\text { Option for data } \\
\text { to be reviewed } \\
\text { locally }\end{array}$ \\
\hline $\begin{array}{l}\text { Is there } \\
\text { patient diary } \\
\text { correlation? }\end{array}$ & Y & $\mathrm{N}$ & Y & $\mathrm{N}$ & Y & $\mathrm{N}$ \\
\hline
\end{tabular}

* Pla

*Placement on sternum thought to improve AF detection compared to other patches but no head to head trials

** We use the Apoplex device for in clinic monitoring, applied at start of clinic and removed after all tests are complete that day 
After non-invasive monitoring, our practice is to proceed to prolonged monitoring via an implanted cardiac monitor in patients whose ischaemic stroke remains unexplained, with a high suspicion of cardiac embolism (e.g. non-lacunar, especially if due to cortical branch occlusion, or in multiple vascular territories, or with other radiological characteristics shown in figure 1), and in whom we would recommend anticoagulation if $A F$ is found. Traditional catheter-inserted monitors have now been replaced by subcutaneous devices, inserted via a $<1 \mathrm{~cm}$ incision, which offer up to 3 years of continuous monitoring, MRI-compatibility, automated arrhythmia detection as well as a patientactivated event alarm, and wireless data download. The Reveal LINQ monitor (figure 3) has recently been the subject of a NICE MedTech Innovation briefing [42]. Such systems are generally welltolerated, being small and lightweight, with a low rate of complications (in CRYSTAL-AF, the removal rate due to infection or erosion was $2.4 \%$ ). Whether their use translates into a reduced risk of stroke is being addressed by the LOOP trial, expected to report in 2020 [43].

\section{Low-burden and implanted device-detected AF}

With the greater use of prolonged monitoring, an increasing number of patients will be found who have short and infrequent paroxysms of AF - that is, a low 'AF burden'. The patients in the key clinical trials of anticoagulation and risk score development cohorts will largely have been diagnosed by short duration monitoring, and are therefore more likely to have had a high AF burden. Therefore, whether low-burden AF patients diagnosed through prolonged monitoring benefit similarly from anticoagulation is an important uncertainty. However, current national and international guidelines do not distinguish by AF burden, and our practice is to consider anticoagulation in any patient with proven AF of any duration. It is likely that AF burden increases over time, and the haemodynamic effects of irregular atrial contraction may not be the only mechanism of intracardiac thrombosis in AF [44]. Most studies correlating AF burden with stroke risk have been performed in patients with pacemakers or implanted cardioverter-defibrillators able to detect paroxysmal atrial tachycardias termed 'atrial high rate episodes' (AHREs). The results of these studies are inconsistent, finding ischaemic stroke risk to be increased variously by the presence of an AHRE $>5$ minutes, 6 minutes or $24 \mathrm{hrs}$, or by a daily burden of $5.5 \mathrm{hrs}$ or more on at least one day during the monitoring period [4549]. AHREs correlate with AF detection on dedicated rhythm monitoring, but imperfectly; therefore, these results should not be extrapolated directly to patients with proven AF. Neurologists should however be aware that interrogation of an implanted cardiac device in a stroke patient may provide evidence of an increased risk of AF, and that two clinical trials (NOAH AFNET-6 and ARTESIA) are testing the benefit of anticoagulation in patients with AHREs lasting less than 24hrs [50,51]. In the meantime, a proposed approach for the management of AHREs, based on European Society of Cardiology guidance, is to consider anticoagulation for patients with a previous ischaemic stroke, or with an AHRE 
$>24 \mathrm{hrs}$ and two or more non-gender risk factors in CHA2DS2VASc [8,52]. For other patients, an AHRE should prompt ECG monitoring, and consideration of anticoagulation if AF is then documented.

\section{Neurogenic AF}

A further complexity concerning AF diagnosed after stroke is that a proportion of this may be caused by abnormal autonomic drive, possibly related to insular brain injury [53], and inflammation, especially if detected in the acute phase. This 'neurogenic' AF could be a transient phenomenon and not require long-term anticoagulation, unlike 'cardiogenic' AF due to structural heart disease [54]. Although there is insufficient supporting evidence to change clinical practice, it has recently been reported that recurrent ischaemic stroke risk in patients diagnosed with AF after stroke is low compared to that of patients known to have AF prior to stroke, and similar to that observed in sinus rhythm [55]. Repeat rhythm monitoring, delayed by several months, might be of value in stratifying the longer-term risk in these patients.

\section{DECIDING ON ANTICOAGULATION}

In AF patients, oral anticoagulation with warfarin reduces the relative risk of ischaemic stroke by approximately two-thirds, regardless of absolute risk [56,57]; this means that those patients at highest absolute risk gain the most absolute benefit from anticoagulation. Direct oral anticoagulants (DOACs) offer similar protection against ischaemic stroke to vitamin $\mathrm{K}$ antagonists (warfarin) [58]. This benefit must be weighed against the risk of anticoagulation-associated haemorrhage, particularly intracerebral haemorrhage $(\mathrm{ICH})$, which is rare (generally less than $1 \%$ per year in clinical trials) but incurs much higher morbidity and mortality than ischaemic stroke [59]. The trade-off between the reduced risk of ischaemic stroke and increased risk of $\mathrm{ICH}$, weighted by severity, has been described as the 'net clinical benefit' of anticoagulation. Overall, using CHADS2 for risk stratification, a positive net clinical benefit is obtained for patients scoring 2 or more [60]. A subsequent analysis using CHA2DS2VASc, which is more accurate than CHADS2 in lower-risk patients, found a small net clinical benefit for patients with a score of 1 [61]. Female patients with a CHA2DS2VASc of 1 (that is, with no other risk factors beyond gender) have a very low risk of ischaemic stroke, comparable to that for men with CHA2DS2VASc of 0, and may not benefit from anticoagulation with warfarin [62]. The threshold for benefit with DOAC use has not been as fully studied, but modelling indicates this is likely to be lower, due to their substantially reduced risk of $\mathrm{ICH}$ [63]. In view of these data, the 2016 European Society of Cardiology guidelines suggest consideration of anticoagulation for any patient with AF and a single non-gender CHA2DS2VASc risk factor [8], as do the 2018 guidelines of the American College of Chest Physicians (ACCP) [64]. The 2014 American Heart Association guidelines endorse anticoagulation for CHA2DS2VASC >1, but suggest no treatment, anticoagulation or aspirin for patients 
with CHA2DS2VASc $=1$, though acknowledge a lack of evidence for aspirin in the prevention of cardioembolic stroke [65].

Having established that a patient has an appreciable ischaemic stroke risk and should be considered for anticoagulation, the next step is to assess bleeding risk. Ideally, it would be possible to calculate the net clinical benefit of anticoagulation for an individual. To this end, several bleeding risk scores have been generated, including HASBLED, HEMORR2HAGES, ATRIA and ORBIT. These scores perform similarly and modestly, with c-statistics for major bleeding between 0.6 and 0.7 [66]. Limitations of risk scores include the use of risk factors which are dynamic and difficult to know prospectively or based on a single assessment (e.g. uncontrolled hypertension, labile INR), the use in some cases of variables not routinely measured in clinical practice (e.g. genetic data in HEMORR2HAGES), their derivation largely for warfarin-treated patients, and the use of a composite 'major bleeding' outcome measure which weights a two-unit transfusion equally to a disabling $\mathrm{ICH}$. Notably, they perform less well for predicting intracranial haemorrhage specifically, the major bleeding risk relevant to anticoagulation decisions in atrial fibrillation, with c-statistics close to 0.5 [67]. Given this, a straightforward comparison of calculated 'major bleeding' and ischaemic stroke risks cannot currently be recommended. However, bleeding risk scores are useful to inform discussions with patients considering anticoagulation, and to identify patients requiring closer monitoring and aggressive treatment of modifiable bleeding risk factors. Patients at particularly high risk of bleeding and stroke may be considered for non-pharmacological treatment, such as left atrial appendage occlusion.

More precise estimation of bleeding risk (including intracranial haemorrhage) might be enabled through the use of MRI biomarkers including cerebral microbleeds (figure 4) [19]. The CROMIS-2 study included 1490 participants with recent ischaemic stroke or TIA and AF; the symptomatic intracranial haemorrhage rate in patients with cerebral microbleeds was 9.8 per 1000 patient-years $(95 \% \mathrm{Cl} 4 \cdot 0$ 20.3) compared with 2.6 per 1000 patient-years (95\% $\mathrm{Cl} 1 \cdot 1-5 \cdot 4)$ in those without cerebral microbleeds (adjusted hazard ratio $3 \cdot 67,95 \% \mathrm{Cl} 1 \cdot 27-10 \cdot 60$ ). Compared with the HAS-BLED score alone, models including cerebral microbleeds predicted symptomatic intracranial haemorrhage significantly better with a c-statistic of $0.74(95 \% \mathrm{Cl} 0.60-0.88)$. Further data from large international collaborative studies are awaited to establish the value of cerebral microbleeds in predicting intracranial haemorrhage.

\section{Anticoagulation in the elderly}

Beyond bleeding risk scores, increasing age is sometimes seen as a contraindication to anticoagulation, particularly in those over 75 years, with antiplatelets sometimes used instead. Older patients are at the highest risk of stroke, so have the most to gain from treatment, and to lose if anticoagulation is needlessly withheld. The BAFTA study [68] showed warfarin to be superior to aspirin 
in stroke prevention in patients aged seventy-five or older (mean age $81.5+/-4.2 \mathrm{yrs}$ ), with a relative risk of all-cause stroke of 0.48 in the warfarin arm. The risk of haemorrhagic complications did not vary significantly between the two groups, and was relatively low overall, with an annual risk of major haemorrhage of $1.9 \%$ with warfarin and $2.0 \%$ with aspirin (and $2.9 \%$ and $3.7 \%$ respectively in those >85yrs). The relative efficacy of warfarin in ischaemic stroke prevention is maintained despite increasing age, so a greater absolute benefit is derived in older, and so higher risk, patients, outweighing a slower increase in ICH risk. Overall, older patients seem to gain a greater net clinical benefit from anticoagulation [69]. Secondary analyses of three pivotal DOAC trials (ARISTOTOLE, ROCKET-AF and RE-LY) show that older patients benefit similarly to younger patients from DOACs $[70,71]$, although the use of dabigatran at the higher dose of $150 \mathrm{mg}$ BD is associated with high rates of extracranial bleeding in those older than 80 years [72]. We therefore do not recommend any upper age cut-off for considering anticoagulation.

\section{Cognitive impairment, frailty, and falls}

These are common reasons for withholding anticoagulation, but this might be unjustified. The use of a DOAC potentially avoids much of the difficulty of warfarin monitoring in cognitively-impaired patients, but measuring adherence might be challenging unless a relative or carer is available to supervise use. Frailty, usually defined as a decline in physiological reserve across multiple systems leading to increased vulnerability to stressors, is independently associated with reduced prescription of anticoagulants [73], but the limited evidence available does not support this: in the ORBIT-AF registry of nearly 10,000 patients, of whom over 500 met AGS criteria for frailty, survival was improved by anticoagulation even in frail patients, and frailty did not independently predict an increased risk of major bleeding or stroke [74]. Falls are cited as a reason to withhold anticoagulation in over a quarter of untreated AF patients [75]. This is understandable: anticoagulation with warfarin triples the risk of subdural haemorrhage [76], thought often due to falls, and frequent falls quadruple the risk of traumatic $\mathrm{ICH}$ [77]. However, ICH after a single fall is rare, even in anticoagulated patients [78], and the risk of subdural haemorrhage in anticoagulated AF patients is very low compared to the risk of ischaemic stroke [76]. As a result, it has been estimated that an AF patient with an $6 \%$ annual ischaemic stroke risk would need to fall 295 times per year not to benefit from warfarin [79]. Although this figure will be lower for patients with a lower ischaemic stroke risk, the average elderly patient who falls does so only 1.8 times each year, and most patients who fall will have an elevated stroke risk because of their age and co-morbidities. Pragmatically, it is also not clear that being screened as "high falls risk' or having fallen in the last year is associated with an increased risk of haemorrhage in anticoagulated patients $[80,81]$. Therefore, we do not recommend withholding anticoagulation in patients who fall, but do suggest a thorough assessment and modification of falls risk where possible. 


\section{STARTING AN ANTICOAGULANT}

2 Most AF patients will be offered a vitamin $\mathrm{K}$ antagonist (VKA; generally, warfarin), a direct thrombin inhibitor (dabigatran), or a factor Xa inhibitor (apixaban, rivaroxaban, edoxaban). The latter classes act directly on components of the common coagulation pathway, so are termed 'direct oral anticoagulants' (DOACs). Compared to warfarin, they have a rapid onset of action, without an initial procoagulant effect, a short half-life, few interactions with food and medication, and do not require dose titration or monitoring blood tests. Their characteristics are summarised in Table 6. In phase three trials, all were at least non-inferior to warfarin for the prevention of stroke and systemic embolism (SES), with about half the rate of intracranial haemorrhage [82-85]. This clinical trial data is strongly supported by data from observational studies in 'real world' populations [86]. Our practice, supported by European guidelines [8], is to recommend a DOAC to all patients without a specific indication for a VKA (e.g. a mechanical prosthetic heart valve or significant mitral stenosis [87]) (box 1). We also generally prefer a VKA (or low molecular weight heparin) in patients with active malignancy, in whom fluctuations in renal function and body weight are common during treatment and disease course. However, a recent analysis of outcomes for patients in ENGAGE-AF-TIMI 48 diagnosed with cancer during the trial found the benefit of edoxaban to be preserved, suggesting that the use of DOACs in these patients should be investigated further [88]. 
Table 6: Summary of oral anticoagulant properties

\begin{tabular}{|c|c|c|c|c|c|}
\hline & Apixaban & Edoxaban & Rivaroxaban & Dabigatran & Warfarin \\
\hline Mechanism & Factor Xa inhibitor & Factor Xa inhibitor & Factor Xa inhibitor & $\begin{array}{l}\text { Direct thrombin } \\
\text { inhibitor }\end{array}$ & $\begin{array}{l}\text { Vitamin } \mathrm{K} \\
\text { antagonist }\end{array}$ \\
\hline Indication & \multicolumn{4}{|c|}{$\begin{array}{ll}\text { Non-valvular AF }+1 \text { of: } \\
\text { - } & \text { Ischaemic stroke/TIA } \\
\text { - } & \text { Age }>75 y r s \\
\text { - } & \text { Symptomatic/congestive HF } \\
\text { - } & \text { DM } \\
- & \text { HTN }\end{array}$} & $\begin{array}{l}\text { Non-valvular AF } \\
\text { Valvular AF } \\
\text { Metallic valve }\end{array}$ \\
\hline Standard dose & $5 \mathrm{mg} \mathrm{BD}$ & $60 \mathrm{mg}$ OD & $20 \mathrm{mg}$ OD & $150 \mathrm{mg} \mathrm{BD}$ & $\begin{array}{l}\text { Dose-adjusted } \\
\text { to INR }\end{array}$ \\
\hline Reduced dose & $\begin{array}{l}2.5 \mathrm{mg} \mathrm{BD} \\
\text { (at least } 2 \text { of: } \\
\text { age }>80 \mathrm{yrs} \text {, weight } \\
<60 \mathrm{~kg}, \mathrm{Cr} \\
>133 \mu \mathrm{mol} / \mathrm{L} \text { ) }\end{array}$ & $\begin{array}{l}30 \mathrm{mg} \mathrm{OD} \\
\text { (any of: } \mathrm{CrCL} \\
<50 \mathrm{ml} / \mathrm{min} \text {, weight } \\
<60 \mathrm{~kg} \text {, concomitant } \\
\text { strong P-gp inhibitor } \\
\text { use) }\end{array}$ & $\begin{array}{l}15 \mathrm{mg} \text { OD } \\
(\mathrm{CrCl}<50 \mathrm{ml} / \mathrm{min})\end{array}$ & $\begin{array}{l}\text { 110mg BD } \\
\text { (>80yrs, verapamil; } \\
\text { also consider if } 75- \\
80 y r s, \mathrm{CrCl} 30- \\
50 \mathrm{ml} / \mathrm{min} \text {, gastritis, } \\
\text { increased bleeding } \\
\text { risk) }\end{array}$ & N/A \\
\hline \multirow[t]{2}{*}{ Contraindications } & \multicolumn{5}{|c|}{ Clinically-significant bleeding or high risk of bleeding complication } \\
\hline & $\begin{array}{ll}- & \mathrm{CrCl} \\
& <15 \mathrm{ml} / \mathrm{min} \\
\text { - } & \text { Severe hepatic } \\
& \text { impairment } \\
\text { - } & \text { Pregnancy } \\
\text { - } & \text { Breast-feeding }\end{array}$ & $\begin{array}{ll}- & \mathrm{CrCl} \\
& <15 \mathrm{ml} / \mathrm{min} \\
\text { - } & \text { Hepatic } \\
& \text { impairment } \\
& \text { with } \\
& \text { coagulopathy } \\
\text { - } & \text { Uncontrolled } \\
& \text { severe HTN } \\
\text { - } & \text { Pregnancy } \\
\text { - } & \text { Breast feeding }\end{array}$ & $\begin{array}{ll}- & \mathrm{CrCl} \\
& <15 \mathrm{ml} / \mathrm{min} \\
- & \text { Hepatic } \\
& \text { impairment } \\
& \text { with } \\
& \text { coagulopathy } \\
\text { - } & \text { Pregnancy } \\
\text { - } & \text { Breast } \\
& \text { feeding }\end{array}$ & $\begin{array}{ll}- & \mathrm{CrCl}<30 \mathrm{ml} / \mathrm{min} \\
\text { - } & \text { Hepatic } \\
& \text { impairment } \\
& \text { expected to } \\
& \text { affect survival } \\
\text { - } & \text { Pregnancy } \\
\text { - } & \text { Breast feeding }\end{array}$ & $\begin{array}{ll}- & \text { Pregnancy } \\
\left(1^{\text {st }} \text { and }\right. \\
3^{\text {rd }} \\
\text { trimester })\end{array}$ \\
\hline Pharmacokinetics & $\begin{array}{l}\text { T1/2: c. } 12 \mathrm{hrs} \\
27 \% \text { renal excretion }\end{array}$ & $\begin{array}{l}\mathrm{T} 1 / 2: 10-14 \mathrm{hrs} \\
35 \% \text { renal excretion }\end{array}$ & $\begin{array}{l}\text { T1/2: } 5-13 \mathrm{hrs} \\
65 \% \text { renal } \\
\text { excretion }\end{array}$ & $\begin{array}{l}\mathrm{T} 1 / 2: 13-18 \mathrm{hrs} \\
80 \% \text { renal excretion }\end{array}$ & $\begin{array}{l}\text { T1/2: } 20- \\
60 \mathrm{hrs} \\
35 \% \text { renal } \\
\text { excretion }\end{array}$ \\
\hline $\begin{array}{l}\text { Summary of } \\
\text { interactions }^{1}\end{array}$ & $\begin{array}{l}\text { Avoid: Strong } \\
\text { CYP3A4 + P-gp } \\
\text { inhibitors }{ }^{2} \\
\text { Caution: Other } \\
\text { CYP3A4/P-gp } \\
\text { inhibitors } 3 \text {, CYP3A4 } \\
\text { inducers }\end{array}$ & $\begin{array}{l}\text { Reduce dose: Strong } \\
\text { P-gp inhibitors } \\
\text { Caution: other P-gp } \\
\begin{array}{l}\text { inhibitors }^{6}, \mathrm{P} \text {-gp } \\
\text { inducers }^{7}\end{array}\end{array}$ & $\begin{array}{l}\text { Avoid: Strong } \\
\text { CYP3A4 + P-gp } \\
\text { inhibitors } \\
\text { Caution: Other } \\
\text { CYP3A4/P-gp } \\
\text { inhibitors, CYP3A4 } \\
\text { inducers }\end{array}$ & $\begin{array}{l}\text { Avoid: strong P-gp } \\
\text { inhibitors, P-gp } \\
\text { inducers } \\
\frac{\text { Reduce dose: }}{\text { verapamil }} \\
\frac{\text { Caution: other P-gp }}{\text { inhibitors }}\end{array}$ & $\begin{array}{l}\text { Extensive } \\
\text { interactions via } \\
\text { CYPP } 450^{8}\end{array}$ \\
\hline \multirow{2}{*}{$\begin{array}{l}\text { Common side- } \\
\text { effects }\end{array}$} & \multicolumn{5}{|c|}{ Bleeding complications } \\
\hline & Nausea & $\begin{array}{l}\text { Dizziness, headache, } \\
\text { abdominal pain, } \\
\text { nausea, itch }\end{array}$ & Itch, headache & $\begin{array}{l}\text { Dyspepsia, abdo pain, } \\
\text { diarrhoea (tartaric } \\
\text { acid excipient) }\end{array}$ & \\
\hline Reversal agent & \multicolumn{3}{|c|}{ Andexanet alfa (FDA-approved, not currently licenced in UK) } & Idarucizumab & $\begin{array}{l}\text { Vitamin K } \\
\text { PTCC }\end{array}$ \\
\hline
\end{tabular}

2

${ }^{1}$ Adapted from manufacturers' SPCs and with reference to [89] ; consulting BNF and local guidelines also suggested

${ }^{2}$ Strong inhibitors of both CYP3A4 and P-gp: ketoconazole, itraconazole, voriconazole, posaconazole, dronedarone, HIV protease inhibitors (increased anticoagulant effect)

${ }^{3}$ Other inhibitors of CYP3A4 and P-gp (i.e. with less potent inhibition of one or both pathways): clarithromycin, erythromycin, fluconazole (increased anticoagulant effect)

${ }^{4}$ CYP3A4 inducers: rifampicin, phenytoin, carbamazepine, phenobarbitone, St. John's wort (reduced anticoagulant effect)

${ }^{5}$ Strong P-gp inhibitors: as (2), also ciclosporin, tacrolimus and erythromycin (increased anticoagulant effect)

${ }^{6}$ Other P-gp inhibitors: verapamil (note dose reduction for dabigatran), amiodarone, quinidine, clarithromycin, ticagrelor (increased anticoagulant effect) 
${ }^{8}$ Major warfarin interactions: allopurinol, azoles, omeprazole, amiodarone, tamoxifen, statins (esp. fluvastatin), fibrates, erythromycin, metronidazole (increased effect); phenobarbitone, primidone, carbamazepine, rifampicin, phenytoin, azathioprine, St. John's wort (reduced effect); steroids, nevirapine, ritonavir (unpredictable effects); liver, broccoli, sprouts, leafy greens (high vitamin K content - reduced effect)

\section{Box 1: Indications for VKAs over DOACs}

- Absolute

- Prosthetic (mechanical) heart valve

- Valvular atrial fibrillation (due to moderate or severe mitral stenosis, usually of rheumatic origin)

- Severe renal impairment

- Relative
- Comorbid malignancy
- Patient choice (e.g. if long-established on warfarin)
- Extremes of body weight (pharmacokinetics/dosing of DOAC unclear)
- Likelihood of poor compliance without monitoring blood tests

\section{Choosing between DOACs}

Some differences were observed in the performance of the DOACs in their phase three trials against warfarin. Dabigatran $150 \mathrm{mg}$ BD, edoxaban $60 \mathrm{mg}$, and apixaban were superior for the prevention of stroke and systemic embolism, mainly driven by a reduced risk of intracerebral haemorrhage, whereas rivaroxaban was non-inferior. Only dabigatran $150 \mathrm{mg}$ BD was superior for prevention of ischaemic stroke. Apixaban, edoxaban and dabigatran 110mg BD were associated with a lower risk of major bleeding, and edoxaban $30 \mathrm{mg}$ with a lower risk of GI bleeding. Dabigatran $150 \mathrm{mg}$ BD and rivaroxaban had higher risks of gastrointestinal bleeding. Given the absence of head-to-head randomised controlled trials, attempts have been made to infer their relative efficacy through network metaanalysis; that is, a systematic assessment of their performance against warfarin as a common comparator. In the largest analysis of this type, the authors concluded that apixaban offered the optimal balance of safety and efficacy, with dabigatran showing the greatest efficacy but a less favourable safety profile [90].

Caution is needed in the interpretation of these results. Although the authors showed a lack of effect modification by age, gender balance or CHADS2, they could not control for other possible sources of confounding. For instance, the ROCKET-AF trial of rivaroxaban included a substantially higher-risk population with more co-morbidities than RE-LY or ARISTOTLE, not all of which are accounted for in the CHADS2 score. There is therefore still a need for high-quality RCT evidence, though large numbers would be needed to compare treatments likely to have similar effect sizes. Until such evidence is 
available, we do not think there is sufficient evidence to make a general recommendation for a particular DOAC; rather, we suggest balancing the available evidence with patient characteristics and preferences in choosing an anticoagulant. For some patients, apixaban might be a reasonable default choice, especially those with impaired renal function. We would consider dabigatran for patients with high ischaemic stroke risk and low bleeding risk, but avoid it in patients with significant dyspepsia or previous major GI bleeding. For patients who prefer once-daily dosing, edoxaban and rivaroxaban may aid compliance. Interactions with other medication should be considered. We recommend the recent American College of Chest Physicians guidelines for further advice on anticoagulant selection [64].

\section{Timing of anticoagulation}

The optimal timing to start anticoagulation after a cardioembolic stroke is unclear. Based on studies of heparin, very early $(<48 \mathrm{hrs})$ anticoagulation increases the risk of symptomatic intracranial haemorrhage without reducing the risk of early recurrence (7-14 days), morbidity or mortality [91]. Current practice is therefore to delay anticoagulation by up to fourteen days. As the risk of recurrence in this time is around 5\%, many clinicians will anticoagulate earlier, according to the size of the infarct and presence of haemorrhagic transformation. The '1-3-6-12' rule-of-thumb, based only on expert opinion, suggests anticoagulation on days 1, 3, 6 and 12 respectively after TIA, minor, moderate and large infarcts [92]. The lower risk of $\mathrm{ICH}$ with DOACs may facilitate earlier anticoagulation, and observational studies do suggest that the risk of symptomatic intracranial haemorrhage in patients treated with DOACs within the first five days of ischaemic stroke is low, as is the risk of new asymptomatic haemorrhagic transformation [93,94], at least in patients with small infarcts . Four large upcoming RCTs, OPTIMAS, TIMING, START and ELAN, will assess the benefit of early anticoagulation (<4 days) in patients with AF-related stroke, with OPTIMAS due to recruit 3500 participants throughout the UK from early 2019 [95].

\section{COMMON CHALLENGES DURING ANTICOAGULATION}

The main challenges encountered in patients established on oral anticoagulation for stroke prevention in atrial fibrillation comprise treatment failure - recurrent ischaemic stroke - and bleeding complications - most seriously, intracerebral haemorrhage (ICH).

\section{Management of recurrent ischaemic stroke}

In this event, the first priority is to determine the patient's eligibility for hyperacute treatment. In patients taking warfarin, point-of-care INR testing provides an immediate answer: an INR of 1.7 or less does not contraindicate thrombolysis [96]. With DOACs, this is less straightforward. Although some standard laboratory clotting indices (particularly the APTT) may be influenced by DOACs, they are not 
reliable markers of the degree of anticoagulation. More valid assays, such as factor Xa levels (for apixaban, edoxaban and rivaroxaban) and dilute thrombin time (dabigatran), are not usually available quickly. In the absence of an assay result excluding a significant DOAC effect, US guidelines advise against thrombolysis unless it can be clearly established that the patient last took a DOAC more than $48 \mathrm{hrs}$ ago and has normal renal function [27]. The European Society of Cardiology recommends also considering thrombolysis for patients who last took a DOAC between 24 and 48hrs ago, if renal function is normal and they are otherwise a good candidate [89]. In patients not meeting these criteria, proceeding directly to mechanical thrombectomy should be considered in patients with thrombus within the basilar artery or proximal middle cerebral artery. Successful thrombolysis has been reported after dabigatran reversal. For patients taking FXa inhibitors, a pathway using a rapid anti-Xa activity assay (RivLev) to guide thrombolysis in patients taking rivaroxaban has been tested successfully in a single centre [97]. Importantly, over half the patients included who would not have been eligible for thrombolysis based on last DOAC intake had a RivLev result compatible with thrombolysis [98]. We are introducing a similar pathway in our centre, and our practice in the absence of a FXa level reflects European guidelines.

Poor compliance is the most obvious cause for treatment failure. In this case, the underlying reasons should be addressed, which may involve continuing the existing treatment with measures to improve compliance or choosing a new OAC more acceptable to the patient (for instance, a FXa inhibitor rather than dabigatran in patients with GI side-effects, a DOAC rather than warfarin in patients reluctant to undergo blood tests, or a once-daily rather than twice daily DOAC). If compliance is good, drug and dietary interactions should be considered. A few patients suffer a recurrent ischaemic stroke despite apparently therapeutic anticoagulation, perhaps due to an alternative mechanism such as atherosclerosis or small vessel occlusion. There is no accepted evidence-based strategy for such patients. Seeking any treatable alternative cause of stroke (e.g. carotid stenosis) or stroke "mimic" is essential. In those on warfarin, a switch to a DOAC might be recommended. Increasing the target INR instead is associated with a high risk of bleeding. In those on DOACs, an alternative DOAC (with a different mechanism of action or more frequent dosing) could be used, or a switch to warfarin could be made if closer monitoring is thought desirable. Adding an antiplatelet is not generally recommended (at least not long-term), as the concurrent use of aspirin with an anticoagulant was associated with increased bleeding but not a reduction in the risk of all-cause stroke and systemic embolism in the RE-LY [99] and SPORTIF [100] trials.

\section{Management of OAC-associated ICH}


The management of oral anticoagulant-associated ICH entails supportive care, rapid reduction of systolic blood pressure to $<140 \mathrm{mmHg}$ [101], and reversal of anticoagulation. For patients taking warfarin, this is achieved with 5-10mg vitamin $\mathrm{K}$ intravenously, and replacement of the vitamin Kdependent clotting factors (II, VII, IX and X) with four-factor prothrombin complex concentrate (e.g. Beriplex, Octaplex) in preference to fresh frozen plasma [102]. For patients taking DOACs, there is no role for vitamin K supplementation, as DOACs act downstream of the vitamin-K dependent portion of the clotting cascade. Four-factor prothrombin complex concentrate has been used off-label, and is recommended by European Heart Rhythm Association guidelines [89], but evidence for efficacy is limited. For dabigatran, a specific monoclonal antibody antidote, idarucizumab, is available, rapidly and safely normalising laboratory clotting indices and achieving normal intra-operative haemostasis in patients needing emergency surgery in an uncontrolled phase three study [103]. We recommend the immediate use of this agent where available in dabigatran-related intracerebral haemorrhage. A decoy protein reversal agent for FXa inhibitors, andexanet alfa, has been tested in a small clinical study [104] and has recently been licensed in the United States. It remains expensive and clinically unproven for FXa inhibitor-related $\mathrm{ICH}$, with a potential procoagulant effect from binding tissue factor, which could account for an increased rate of thrombosis reported [103]. Thus, if available, adexanet alfa can be considered for FXa-associated intracerebral haemorrhage, ideally as part of a randomised controlled trial. Nevertheless, even without the use of a reversal agent, the outcome in patients with DOAC-related ICH is no worse than that of patients with VKA-ICH in whom anticoagulation is reversed [105].

Because of the early risk of haematoma expansion, anticoagulation is commonly withheld for at least two weeks after anticoagulant-related ICH even in patients with a strong indication (most often AF). After this, the decision whether to restart anticoagulation is challenging. A meta-analysis of observational studies found that resuming anticoagulation reduces the risk of ischaemic stroke without increasing the risk of haemorrhage [106], with a median time to resumption of $10-39$ days. Nationwide observational data from Sweden also suggests benefit from resuming anticoagulation, estimating the optimal timing to be 7-8 weeks after ICH [107]. Although it is likely that these results are subject to bias, with lower-risk patients more likely to be selected for resumption of anticoagulation, this does suggest that at least some patients can safely resume anticoagulation. Several RCTs - including SOSTART, APACHE-AF and PRESTIGE-AF - will provide more definitive evidence, and an individual patient data meta-analysis is planned through the COCROACH collaboration. In the interim, we suggest a careful re-evaluation of the bleeding and stroke risks, including ICH location (as the recurrence risk of lobar haemorrhage is about four times greater than non-lobar haemorrhage [108]) and MR imaging markers of cerebral amyloid angiopathy [109], careful 
control of modifiable risk factors, and use of a DOAC in preference to warfarin. We strongly encourage randomisation of eligible patients into ongoing trials, but left atrial appendage occlusion may reasonably be considered if the risk of recurrent ICH is judged to be unacceptably high.

\section{MANAGEMENT IN SPECIAL CIRCUMSTANCES}

\section{When anticoagulation is contraindicated}

In reality, there is no agreement on what constitutes an absolute long-term "contraindication" to oral anticoagulation but, rather, a spectrum of risk which can change over time. As clinical data indicate that $90 \%$ of all cardiac thrombi in non-rheumatic AF originate from the left atrial appendage (LAA) [110], exclusion of the left atrial appendage from the circulation offers an alternative strategy for stroke prevention in patients in whom OAC is thought to be unacceptably high-risk. Surgical excision of the LAA is undertaken in patients undergoing cardiac surgery (e.g. mitral valve or MAZE procedures) and is highly unlikely to be offered as an independent intervention purely to reduce stroke risk, whereas catheter-based left atrial appendage closure devices can achieve minimally invasive LAA occlusion (LAAO).

The Boston Scientific Watchman is FDA approved. In two prospective RCTs comparing the Watchman to warfarin (PROTECT-AF [111] and PREVAIL [112]), LAAO was not, overall, inferior for the endpoint of ischaemic stroke and systemic embolism, although there was a higher rate of early, interventionrelated, complications including ischaemic stroke. Ischaemic events after the first 7 days were not significantly different, but rates of major bleeding and particularly haemorrhagic stroke, were significantly lower in the LAAO-managed groups. The overall findings persisted over 5-year follow-up, indicating that the devices are comparable to warfarin in reducing the rate of ischaemic stroke but with a lower risk of haemorrhage (particularly intracerebral haemorrhage) [113]. The European Society of Cardiology AF Management guidelines [8] recommend that LAAO be used in high-risk patients in whom warfarin is contra-indicated (Illb indication, level of evidence B). The recent American College of Chest Physicians guidelines also suggest LAAO in patients with a strong contraindication to oral anticoagulation [64].

However, these LAAO trials were undertaken in predominantly intermediate risk patients (CHA2DS2VASc 1-2) and excluded patients in whom warfarin was contraindicated. The Watchman also requires short-term oral anticoagulation, and, based on currently-available data, long-term antiplatelet therapy. This appears anomalous to the clinical guideline recommendations: it seems unlikely that many patients with a true contraindication to long-term anticoagulation would tolerate short-term anticoagulation and long-term antiplatelet therapy [114]. Observational evidence suggests 
that dual antiplatelet therapy for three to six months in place of anticoagulation may be a safe alternative, even in patients with previous $\mathrm{ICH}[115,116]$. However, given that long-term single antiplatelet therapy is still mandated, which arguably has a bleeding risk similar to DOAC therapy [117], it remains unclear whether LAAO offers a clear benefit over contemporary medical therapy. It should also be noted that incomplete LAA occlusion may increase thromboembolic risk and so mandate anticoagulation [114], and that the insertion procedure is not without risk (notably, a roughly $3 \%$ risk across PREVAIL and PROTECT-AF of serious pericardial effusion requiring treatment). Therefore, though LAAO is supported by current international guidelines and is an option that should be discussed with the cardiologists, the key clinical trials have yet to be performed to demonstrate its efficacy and safety in moderate- and high-risk patients.

There is also interest in whether electrophysiological ablation can reduce ischaemic stroke risk in AF. We believe this should be viewed as a potential adjunct to anticoagulation, not an alternative, not least due to the risk of AF recurrence [118]. Although there is observational evidence to suggest ablation may reduce stroke risk [119], the recent CABANA trial of ablation against medical therapy (both with anticoagulation) did not meet its primary end-point of a composite of death, disabling stroke, major bleeding and cardiac arrest in an intention-to-treat analysis [120]. While there was a high cross-over rate from ablation to medical treatment, and a positive result was obtained in a per protocol analysis, publication of the detailed results is awaited, and per protocol findings should be considered hypothesis-generating.

\section{Embolic Stroke of Undetermined Source}

20-25\% of ischaemic strokes remain cryptogenic despite routine investigations, including noninvasive monitoring. Many of these may be embolic, for instance from low-risk cardiac sources, aortic arch or non-occlusive carotid plaque, or covert paroxysmal AF [121]. It has been argued that anticoagulation in these patients might be more effective in reducing stroke risk than an antiplatelet. The concept of "embolic stroke of undetermined source" (ESUS) as a target for anticoagulation has been tested in three clinical trials. NAVIGATE ESUS was recently stopped early on the basis of a planned interim analysis showing an excess of bleeding with rivaroxaban 15mg OD compared to aspirin, and a low probability of a reduction in stroke risk [122]. RE-SPECT ESUS, with a similar design using dabigatran, is yet to finally report [123]; however, data presented in abstract form at the World Stroke Conference in October 2018 reported the rate of recurrent stroke (primary outcome) was 4.1\% per year with dabigatran and $4.8 \%$ per year with aspirin ( $H R$ 0.85; $P=0.1$ ). The rate of major bleeding was similar in both arms - $1.7 \%$ per year with dabigatran and $1.4 \%$ per year with aspirin. ATTICUS will 
test apixaban in a population enriched for probable cardioembolism, with radiological re-infarction at 12 months as the primary end point [124].

As well as the echocardiographic markers (left atrial dilation, spontaneous LAA echo contrast, reduced LAA flow velocity) used for patient selection in ATTICUS, ECG markers of left atrial function may have a role in identifying ESUS patients more likely to benefit from anticoagulation. For example, increased $p$-wave terminal force, defined as the amplitude of the terminal negative deflection of the $p$-wave in lead V1 multiplied by its duration, is a risk factor for cryptogenic or cardioembolic stroke, even in patients without AF [125]. This lends support to the concept of "left atrial cardiopathy" as an independent cause of cardioembolic stroke and a potential target for future anticoagulation trials [44]. However, in the absence of positive trial results, we recommend usual antiplatelet treatment combined with intensive investigation for established high-risk cardiac sources in patients with suspected but unproven cardioembolic stroke.

\section{Patients with Cardiovascular Comorbidities}

Whereas cardio-embolism is most effectively prevented by anticoagulation, atherosclerotic disease affecting the coronary, cervical or peripheral arteries is usually treated with an antiplatelet, based on the pathophysiological concept of the 'red', fibrin-rich thrombus forming under slow-flow conditions and the 'white', platelet-rich thrombus forming on ulcerated plaque. Arterial disease is common in AF patients, sometimes prompting dual therapy. Large registry studies indicate that combining warfarin and an antiplatelet clearly increases bleeding risk [126] without improving cardiovascular outcomes in patients with coronary or peripheral arterial disease $[127,128]$. Post-hoc analyses of ROCKET-AF suggest a similar pattern with rivaroxaban [129]. The distinction between anticoagulation- and antiplatelet-responsive thrombi is unlikely to be absolute - for instance, both warfarin and rivaroxaban have shown efficacy in place of an antiplatelet in treating coronary artery disease $[130,131]$. Reflecting European Heart Rhythm Association guidelines, in anticoagulated AF patients, we do not add an antiplatelet for secondary prevention in atherosclerotic disease. In patients with AF undergoing $\mathrm{PCl}$, triple therapy with dual antiplatelets and a DOAC is generally recommended for 1 to 6 months (based on an assessment of atherothrombotic and bleeding risk), then dual therapy to complete 12 months, then anticoagulation monotherapy. In patients with severe or symptomatic carotid stenosis, endarterectomy should be performed in preference to stenting, with the addition of aspirin immediately before surgery, and for ten days afterwards [89].

The findings of the COMPASS trial [131] raise a possible alternative approach to stroke prevention in $\mathrm{AF}$ patients with atherosclerotic comorbidities. The combination of rivaroxaban $2.5 \mathrm{mg} \mathrm{BD}$ and aspirin improved cardiovascular outcomes, including ischaemic stroke risk, in a population with stable 
atherosclerotic cardiovascular disease compared to aspirin alone, whereas rivaroxaban $5 \mathrm{mg}$ BD alone did not. These results may also have implications for AF patients who suffer a recurrent ischaemic stroke despite therapeutic anticoagulation. However, both rivaroxaban doses used were low compared to that used for stroke prevention in $A F$, and very few patients with $A F$ were included (392/27395). RCT evaluation of such an approach in AF patients with atherosclerotic comorbidities might be of interest.

\section{CONCLUSION}

8

Box 2: Key Points

- Atrial fibrillation increases ischaemic stroke risk five-fold and justifies anticoagulation in the vast majority of patients, even those who are old, frail or have had falls.

- DOACs are at least as effective as warfarin and offer a much lower risk of intracranial haemorrhage, so should be preferred for most patients.

- The yield of investigation for AF after stroke is high, and will increase as advanced noninvasive and implanted monitors become more widely available.

- When anticoagulation fails and recurrent ischaemic stroke occurs, thrombolysis may be possible even in patients using DOACs.

- Even after anticoagulant-related ICH, restarting anticoagulation might be beneficial, though LAAO can be considered in patients at very high risk of $\mathrm{ICH}$ recurrence. 


\section{AUTHORSHIP STATEMENT}

2 DW had the idea for the article and developed the outline with JB. JB, RB, MH, AC and DW wrote the manuscript and are responsible for its content.

\section{FUNDING}

5 DW receives research funding support from the British Heart Foundation and the Stroke Association.

6 This work was undertaken at University College London Hospitals NHS Foundation Trust/University

7 College London, who received a proportion of funding from the Department of Health's National Institute for Health Research Biomedical Research Centres funding scheme.

\section{FIGURE LEGENDS}

Figure 1:

MR imaging showing patterns of acute infarction associated with cardioembolism.

Top row, from left: diffusion-weighted imaging showing isolated cortical infarct, small wedge-shaped predominantly cortical infarct, and medium-sized cortico-subcortical infarct; T2 weighted imaging showing large wedge-shaped infarct with $\mathrm{T} 2$ hypointensity indicating haemorrhagic transformation.

Bottom row, left to right: PCA territory infarction, scattered cortical and subcortical infarcts within right MCA territory, striatocapsular infarction with additional small right MCA territory infarcts (suggesting transient M1 occlusion then fragmentation and distal embolization of thrombus), scattered bihemispheric lesions.

Figure 2:

Patch and lead monitoring devices (left to right): e-Patch, Zio, CAM, R-test, Apoplex

Figure 3:

The Reveal-LINQ is a small implanted cardiac monitor, inserted subcutaneously in the precordium via a $<1 \mathrm{~cm}$ incision.

Figure 4:

Cerebral microhaemorrhages and intracerebral haemorrhage. Left to right: small left frontal cortical infarct demonstrated on DWI in a patient with atrial fibrillation; susceptibility-weighted imaging shows multiple lobar microhaemorrhages (arrowed); lobar ICH two years after initiation of anticoagulation. 
21 Davis RC, Hobbs FDR, Kenkre JE, et al. Prevalence of atrial fibrillation in the general population and in high-risk groups: The ECHOES study. Europace 2012;14:1553-9. doi:10.1093/europace/eus087

2 Sposato LA, Cipriano LE, Saposnik G, et al. Diagnosis of atrial fibrillation after stroke and transient ischaemic attack: A systematic review and meta-analysis. Lancet Neurol 2015;14:377-87. doi:http://dx.doi.org/10.1016/S1474-4422\%2815\%2970027-X Wolf $\mathrm{P}$ a, Abbott RD, Kannel WB. Original Contributions Atrial Fibrillation as an Independent Risk Factor for Stroke : The Framingham Study. Stroke 1991;22:983-8. doi:10.1161/01.STR.22.8.983 Gowers WR. ON A CASE OF SIMULTANEOUS EMBOLISM OF CENTRAI RETINAL AND MIDDLE CEREBRAL ARTERIES. Lancet 1875;106:794-6. doi:10.1016/S0140-6736(02)30705-0 Hay WE, Levine SA. Age and auricular fibrillation as independent factors in auricular mural thrombus formation. Am Heart J 1942;24:1-3. doi:10.1016/S0002-8703(42)91013-5 FISHER M, ADAMS RD. Observations on brain embolism with special reference to the mechanism of hemorrhagic infarction. J Neuropathol Exp Neurol 1951;10:92-4.

Wolf PA, Dawber TR, Thomas HE, et al. Epidemiologic assessment of chronic atrial fibrillation and risk of stroke: the Framingham study. Neurology 1978;28:973-7. doi:10.1212/WNL.28.10.973

Kirchhof P, Benussi S, Kotecha D, et al. 2016 ESC Guidelines for the management of atrial fibrillation developed in collaboration with EACTS. Eur Heart J 2016;37:2893-962. doi:10.1093/eurheartj/ehw210 January CT, Wann LS, Alpert JS, et al. 2014 AHA/ACC/HRS Guideline for the Management of Patients With Atrial Fibrillation. J Am Coll Cardiol 2014;64:e1-76. doi:10.1016/j.jacc.2014.03.022

Verma A, Cairns JA, Mitchell LB, et al. 2014 focused update of the Canadian cardiovascular society guidelines for the management of atrial fibrillation. Can J Cardiol 2014;30:1114-30. doi:10.1016/j.cjca.2014.08.001 and predictors during aspirin therapy. J Am Coll Cardiol 2000;35:183-7. doi:10.1016/S0735- 
1097(99)00489-1

2 Vanassche T, Lauw MN, Eikelboom JW, et al. Risk of ischaemic stroke according to pattern of atrial fibrillation: Analysis of 6563 aspirin-treated patients in active-a and averroes. Eur Heart J 2015;36:281-7. doi:10.1093/eurheartj/ehu307

13 Padfield GJ, Steinberg C, Swampillai J, et al. Progression of paroxysmal to persistent atrial fibrillation: 10-year follow-up in the Canadian Registry of Atrial Fibrillation. Hear Rhythm 2017;14:801-7. doi:10.1016/j.hrthm.2017.01.038

14 Atrial Fibrillation Investigators. Risk factors for stroke and efficacy of antithrombotic therapy in atrial fibrillation. Analysis of pooled data from five randomized controlled trials. Arch Intern Med 1994;154:1449-57. doi:10.1001/archinte.1994.00420130036007 Hart RG, Pearce LA, McBride R, et al. Factors associated with ischemic stroke during aspirin therapy in atrial fibrillation: Analysis of 2012 participants in the SPAF I-III clinical trials. Stroke 1999;30:1223-9. doi:10.1161/01.STR.30.6.1223

Gage BF, Waterman AD, Shannon W, et al. Validation of clinical classification schemes for predicting stroke: results from the National Registry of Atrial Fibrillation. JAMA 2001;285:2864-70. doi:10.1001/jama.285.22.2864

17 Lip GYH, Nieuwlaat R, Pisters R, et al. Refining clinical risk stratification for predicting stroke and thromboembolism in atrial fibrillation using a novel risk factor-based approach: The Euro Heart Survey on atrial fibrillation. Chest 2010;137:263-72. doi:10.1378/chest.09-1584

Szymanski FM, Lip GYH, Filipiak KJ, et al. Stroke Risk Factors Beyond the CHA2DS2-VASc Score: Can We Improve Our Identification of "High Stroke Risk" Patients With Atrial Fibrillation? Am J Cardio/ 2015;116:1781-8. doi:10.1016/j.amjcard.2015.08.049

19 Wilson D, Ambler G, Shakeshaft C, et al. Cerebral microbleeds and intracranial haemorrhage risk in patients anticoagulated for atrial fibrillation after acute ischaemic stroke or transient ischaemic attack (CROMIS-2): a multicentre observational cohort study. Lancet Neurol 2018;17:539-47. doi:10.1016/S1474-4422(18)30145-5

20 Hijazi Z, Lindbäck J, Alexander JH, et al. The ABC (age, biomarkers, clinical history) stroke risk score: A biomarker-based risk score for predicting stroke in atrial fibrillation. Eur Heart J 2016;37:1582-90. doi:10.1093/eurheartj/ehw054

21 Chan YH, Yiu KH, Lau KK, et al. The CHADS2and CHA2DS2-VASc scores predict adverse vascular function, ischemic stroke and cardiovascular death in high-risk patients without 
atrial fibrillation: Role of incorporating PR prolongation. Atherosclerosis 2014;237:504-13. doi:10.1016/j.atherosclerosis.2014.08.026

Mitchell LB, Southern D a, Galbraith D, et al. Prediction of stroke or TIA in patients without atrial fibrillation using CHADS2 and CHA2DS2-VASc scores. Heart 2014;:1-7. doi:10.1136/heartjnl-2013-305303

23 Saliba W, Gronich N, Barnett-Griness O, et al. Usefulness of CHADS2 and CHA2DS2-VASc Scores in the Prediction of New-Onset Atrial Fibrillation: A Population-Based Study. Am J Med 2016;129:843-9. doi:10.1016/j.amjmed.2016.02.029

24 Jain V, Marshall IJ, Crichton SL, et al. Trends in the prevalence and management of pre-stroke atrial fibrillation, the South London Stroke Register, 1995-2014. PLoS One 2017;12:1-12. doi:10.1371/journal.pone.0175980

25 SSNAP. Sentinel Stroke National Audit Programme National Results (Dec 17 - Mar 18). 2018.https://www.strokeaudit.org/results/Clinical-audit/National-Results.aspx\%0D (accessed 26 Nov 2018).

26 Intercollegiate Stroke Working Party. National clinical guideline for stroke. R Coll Physicians London 2016.

27 Powers WJ, Rabinstein AA, Ackerson T, et al. 2018 Guidelines for the Early Management of Patients With Acute Ischemic Stroke: A Guideline for Healthcare Professionals From the American Heart Association/American Stroke Association. 2018. doi:10.1161/STR.0000000000000158

28 Kirchhof P, Benussi S, Kotecha D, et al. 2016 ESC Guidelines for the management of atrial fibrillation developed in collaboration with EACTS. Eur. Heart J. 2016;37. doi:10.1093/eurheartj/ehw210

29 Sanna T, Diener H-C, Passman RS, et al. Cryptogenic Stroke and Underlying Atrial Fibrillation. N Engl J Med 2014;370:2478-86. doi:10.1056/NEJMoa1313600

30 Gladstone DJ, Spring M, Dorian P, et al. Atrial Fibrillation in Patients with Cryptogenic Stroke. N Engl J Med 2014;370:2467-77. doi:10.1056/NEJMoa1311376

31 Wachter R, Gröschel K, Gelbrich G, et al. Holter-electrocardiogram-monitoring in patients with acute ischaemic stroke (Find-AFRANDOMISED): an open-label randomised controlled trial. Lancet Neurol 2017;16:282-90. doi:10.1016/S1474-4422(17)30002-9 
132 Brachmann J, Morillo CA, Sanna T, et al. Uncovering atrial fibrillation beyond short-term monitoring in cryptogenic stroke patients: Three-year results from the cryptogenic stroke and underlying atrial fibrillation trial. Circ Arrhythmia Electrophysiol 2016;9:1-10. doi:10.1161/CIRCEP.115.003333

Arboix A, García-Eroles L, Massons JB, et al. Atrial fibrillation and stroke: clinical presentation of cardioembolic versus atherothrombotic infarction. Int J Cardiol 2000;73:33-42. doi:10.1016/S0167-5273(99)00214-4

Friberg L, Rosenqvist M, Lindgren A, et al. High Prevalence of Atrial Fibrillation Among Patients With Ischemic Stroke. Stroke 2014;45:2599-605. doi:10.1161/STROKEAHA.114.006070 Kwong C, Ling AY, Crawford MH, et al. A Clinical Score for Predicting Atrial Fibrillation in Patients with Cryptogenic Stroke or Transient Ischemic Attack. Cardiology 2017;138:133-40. doi:10.1159/000476030

Thijs VN, Brachmann J, Morillo CA, et al. Predictors for atrial fibrillation detection after cryptogenic stroke: Results from CRYSTAL AF. Neurology 2016;86:261-9. doi:10.1212/WNL.0000000000002282 Gladstone DJ, Dorian P, Spring M, et al. Atrial Premature Beats Predict Atrial Fibrillation in Cryptogenic Stroke: Results from the EMBRACE Trial. Stroke 2015;46:936-41. doi:10.1161/STROKEAHA.115.008714 Sachdeva G, Saeed A, Jani V, et al. Radiological Portrait of Embolic Strokes. Cardiol Clin 2016;34:269-78. doi:10.1016/j.ccl.2015.12.008

Cacciatore A, Russo LS. Lacunar infarction as an embolic complication of cardiac and arch angiography. Stroke 1991;22:1603-5. doi:10.1161/01.STR.22.12.1603

40 Demeestere J, Fieuws S, Lansberg MG, et al. Detection of Atrial Fibrillation Among Patients With Stroke Due to Large or Small Vessel Disease: A Meta-Analysis. J Am Heart Assoc 2016;5:1-8. doi:10.1161/JAHA.116.004151

41 Innovation Network SL. Single-time point case finding for Atrial Fibrillation: A review of methods of delivery and devices. 2017.www.londonscn.nhs.uk/wpcontent/uploads/2017/06/hin-single-time-point-case-finding-af-methods-devices-062017.pdf (accessed 21 Aug 2018). 
strok atrial fibrillation after cryptogenic stroke e Medtech innovation briefing. 2018;:115.https://www.nice.org.uk/advice/mib141/resources/reveal-linq-insertable-cardiacmonitor-to-detect-atrial-fibrillation-after-cryptogenic-stroke-pdf-2285963451125701

3 Svendsen J. Atrial Fibrillation Detected by Continuous ECG monitoring (LOOP). https://clinicaltrials.gov/ct2/show/NCT02036450 (accessed 19 Nov 2018).

44 Kamel H, Okin PM, Elkind MSV, et al. Atrial Fibrillation and Mechanisms of Stroke: Time for a New Model. Stroke 2016;47:895-900. doi:10.1161/STROKEAHA.115.012004

45 Boriani G, Glotzer T V., Santini M, et al. Device-detected atrial fibrillation and risk for stroke: An analysis of $>10000$ patients from the SOS AF project (Stroke preventiOn Strategies based on Atrial Fibrillation information from implanted devices). Eur Heart J 2014;35:508-16. doi:10.1093/eurheartj/eht491 Healey JS, Connolly SJ, Gold MR, et al. Subclinical Atrial Fibrillation and the Risk of Stroke. $N$ Engl J Med 2012;366:120-9.

47 Van Gelder IC, Healey JS, Crijns HJGM, et al. Duration of device-detected subclinical atrial fibrillation and occurrence of stroke in ASSERT. Eur Heart J 2017;38:1339-44. doi:10.1093/eurheartj/ehx042

Glotzer T V., Hellkamp AS, Zimmerman J, et al. Atrial high rate episodes detected by pacemaker diagnostics predict death and stroke: Report of the atrial diagnostics ancillary study of the MOde Selection Trial (MOST). Circulation 2003;107:1614-9. doi:10.1161/01.CIR.0000057981.70380.45

Glotzer T V., Daoud EG, Wyse DG, et al. The Relationship between daily atrial tachyarrhythmia burden from implantable device diagnostics and stroke risk the trends study. Circ Arrhythmia Electrophysiol 2009;2:474-80. doi:10.1161/CIRCEP.109.849638

50 Kirchhof $\mathrm{P}$, Blank $\mathrm{BF}$, Calvert $\mathrm{M}$, et al. Probing oral anticoagulation in patients with atrial high rate episodes: Rationale and design of the Non-vitamin $\mathrm{K}$ antagonist Oral anticoagulants in patients with Atrial High rate episodes (NOAH-AFNET 6) trial. Am Heart J 2017;190:12-8. doi:10.1016/j.ahj.2017.04.015

51 Lopes RD, Alings M, Connolly SJ, et al. Rationale and design of the Apixaban for the Reduction of Thrombo-Embolism in Patients With Device-Detected Sub-Clinical Atrial Fibrillation (ARTESiA) trial. Am Heart J 2017;189:137-45. doi:10.1016/j.ahj.2017.04.008

52 Camm AJ, Simantirakis E, Goette A, et al. Atrial high-rate episodes and stroke prevention. 
Scheitz JF, Erdur H, Haeusler KG, et al. Insular Cortex Lesions, Cardiac Troponin, and Detection of Previously Unknown Atrial Fibrillation in Acute Ischemic Stroke. Stroke Published Online First: 2015. doi:10.1161/STROKEAHA.115.008681

Cerasuolo JO, Cipriano LE, Sposato LA. The complexity of atrial fibrillation newly diagnosed after ischemic stroke and transient ischemic attack: Advances and uncertainties. Curr Opin Neurol 2017;30:28-37. doi:10.1097/WCO.0000000000000410 Sposato LA, Cerasuolo JO, Cipriano LE, et al. Atrial fibrillation detected after stroke is related to a low risk of ischemic stroke recurrence. Neurology 2018;90:e924-31. doi:10.1212/WNL.0000000000005126 RG H, Benavente $\mathrm{O}, \mathrm{McBride} \mathrm{R}$, et al. Antithrombotic therapy to prevent stroke in patients with atrial fibrillation: A meta-analysis. Ann Intern Med 1999;131:492501.http://dx.doi.org/10.7326/0003-4819-131-7-199910050-00003 Hart RG, Pearce LA, Aguilar MI. Meta-analysis : Antithrombotic Therapy to Prevent Stroke in Patients Who Have Nonvalvular Atrial Fibrillation. Ann Intern Med 2007;146:857-67.

Ruff CT, Giugliano RP, Braunwald E, et al. Comparison of the efficacy and safety of new oral anticoagulants with warfarin in patients with atrial fibrillation: A meta-analysis of randomised trials. Lancet 2014;383:955-62. doi:10.1016/S0140-6736(13)62343-0

Wilson D, Seiffge DJ, Traenka C, et al. Outcome of intracerebral hemorrhage associated with different oral anticoagulants. Neurology 2017;88:1693 LP1700.http://n.neurology.org/content/88/18/1693.abstract

Singer DE, Chang Y, Fang MC, et al. The Net Clinical Benefit of Warfarin Anticoagulation in Atrial Fibrillation. Ann Intern Med 2009;151:297-305.

Friberg L, Rosenqvist M, Lip GYH. Net clinical benefit of warfarin in patients with atrial fibrillation: A report from the Swedish atrial fibrillation cohort study. Circulation 2012;125:2298-307. doi:10.1161/CIRCULATIONAHA.111.055079

Lip GYH, Skjøth F, Rasmussen LH, et al. Oral anticoagulation, aspirin, or no therapy in patients with nonvalvular af with 0 or 1 stroke risk factor based on the doi:10.1016/j.jacc.2015.01.044 
Banerjee A, Lane DA, Torp-Pedersen C, et al. Net clinical benefit of new oral anticoagulants (dabigatran, rivaroxaban, apixaban) versus no treatment in a 'real world' atrial fibrillation population: A modelling analysis based on a nationwide cohort study. Thromb Haemost 2011;107:584-9. doi:10.1160/TH11-11-0784

4 H Lip GY, Banerjee A, Boriani G, et al. Antithrombotic Therapy for Atrial Fibrillation CHEST Guideline and Expert Panel Report. Published Online First: 2018. doi:10.1016/j.chest.2018.07.040 January CT, Wann LS, Alpert JS, et al. 2014 AHA/ACC/HRS guideline for the management of patients with atrial fibrillation: A report of the American College of cardiology/American heart association task force on practice guidelines and the heart rhythm society. 2014. doi:10.1161/CIR.0000000000000041 Senoo K, Proietti M, Lane DA, et al. Evaluation of the HAS-BLED, ATRIA, and ORBIT Bleeding Risk Scores in Patients with Atrial Fibrillation Taking Warfarin. Am J Med 2016;129:600-7. doi:10.1016/j.amjmed.2015.10.001

67 Chao TF, Lip GYH, Lin YJ, et al. Major bleeding and intracranial hemorrhage risk prediction in patients with atrial fibrillation: Attention to modifiable bleeding risk factors or use of a bleeding risk stratification score? A nationwide cohort study. Int J Cardiol 2018;254:157-61. doi:10.1016/j.ijcard.2017.11.025

Mant J, Hobbs FR, Fletcher K, et al. Warfarin versus aspirin for stroke prevention in an elderly community population with atrial fibrillation (the Birmingham Atrial Fibrillation Treatment of the Aged Study, BAFTA): a randomised controlled trial. Lancet 2007;370:493-503. doi:10.1016/S0140-6736(07)61233-1

Van Walraven C, Hart RG, Connolly S, et al. Effect of age on stroke prevention therapy in patients with atrial fibrillation: The atrial fibrillation investigators. Stroke 2009;40:1410-6. doi:10.1161/STROKEAHA.108.526988

70 Halvorsen S, Atar D, Yang H, et al. Efficacy and safety of apixaban compared with warfarin according to age for stroke prevention in atrial fibrillation: Observations from the ARISTOTLE trial. Eur Heart J 2014;35:1864-72. doi:10.1093/eurheartj/ehu046

71 Halperin JL, Hankey GJ, Wojdyla DM, et al. Efficacy and safety of rivaroxaban compared with warfarin among elderly patients with nonvalvular atrial fibrillation in the rivaroxaban once daily, oral, direct factor xa inhibition compared with vitamin k antagonism for prevention of 
stroke and embolism. Circulation 2014;130:138-46.

doi:10.1161/CIRCULATIONAHA.113.005008

Lauw MN, Eikelboom JW, Coppens M, et al. Effects of dabigatran according to age in atrial fibrillation. Heart 2017;103:1015-23. doi:10.1136/heartjnl-2016-310358

73 Lefebvre MCD, St-Onge M, Glazer-Cavanagh M, et al. The Effect of Bleeding Risk and Frailty Status on Anticoagulation Patterns in Octogenarians With Atrial Fibrillation: The FRAIL-AF Study. Can J Cardiol 2016;32:169-76. doi:10.1016/j.cjca.2015.05.012

4 Madhavan M, Simon D, Piccini J, et al. Does Frailty Alter the Benefits of Oral Anticoagulation in Patients With Atrial Fibrillation? J Am Coll Cardiol 2017;69:448. doi:http://dx.doi.org/10.1016/S0735-1097(17)33837-8

75 McGrath ER, Go AS, Chang Y, et al. Use of Oral Anticoagulant Therapy in Older Adults with Atrial Fibrillation After Acute Ischemic Stroke. J Am Geriatr Soc 2017;65:241-8. doi:10.1111/jgs.14688

76 Connolly BJ, Pearce LA, Hart RG. Vitamin K antagonists and risk of subdural hematoma: Metaanalysis of randomized clinical trials. Stroke 2014;45:1672-8. doi:10.1161/STROKEAHA.114.005430

Gage BF, Birman-Deych E, Kerzner R, et al. Incidence of intracranial hemorrhage in patients with atrial fibrillation who are prone to fall. Am J Med 2005;118:612-7. doi:10.1016/j.amjmed.2005.02.022

78 Bond AJ, Molnar FJ, Li M, et al. The risk of hemorrhagic complications in hospital in-patients who fall while receiving antithrombotic therapy. Thromb J 2005;3:1-6. doi:10.1186/14779560-3-1

79 Man-Son-Hing M, Nichol G, Lau a, et al. Choosing antithrombotic therapy for elderly patients with atrial fibrillation who are at risk for falls. Arch Intern Med 1999;159:677-85. doi:10.1001/archinte.159.7.677

80 Dodson JA, Petrone A, Gagnon DR, et al. Incidence and determinants of traumatic intracranial bleeding among older veterans receiving warfarin for atrial fibrillation. JAMA Cardiol 2016;1:65-72. doi:10.1001/jamacardio.2015.0345

81 Donzé J, Clair C, Hug B, et al. Risk of falls and major bleeds in patients on oral anticoagulation therapy. Am J Med 2012;125:773-8. doi:10.1016/j.amjmed.2012.01.033 
82 Connolly SJ, Ezekowitz MD, Yusuf S, et al. Dabigatran versus Warfarin in Patients with Atrial Fibrillation. N Engl J Med 2009;361:1139-51. doi:10.1056/NEJMoa0905561 Patel MR, Mahaffey KW, Garg J, et al. Rivaroxaban versus Warfarin in Nonvalvular Atrial Fibrillation. N Engl J Med 2011;365:883-91. doi:10.1056/NEJMoa1009638 Granger CB, Alexander JH, McMurray JJ V, et al. Apixaban versus Warfarin in Patients with Atrial Fibrillation. N Engl J Med 2011;365:981-92. doi:10.1056/NEJMoa1107039 Giugliano RP, Ruff CT, Braunwald E, et al. Edoxaban versus Warfarin in Patients with Atrial Fibrillation. N Engl J Med 2013;369:2093-104. doi:10.1056/NEJMoa1310907

Ntaios G, Papavasileiou V, Makaritsis K, et al. Real-World Setting Comparison of Nonvitamin-K Antagonist Oral Anticoagulants Versus Vitamin-K Antagonists for Stroke Prevention in Atrial Fibrillation: A Systematic Review and Meta-Analysis. Stroke 2017;48:2494-503. doi:10.1161/STROKEAHA.117.017549

Heidbuchel $H$, Verhamme $P$, Alings $M$, et al. EHRA practical guide on the use of new oral anticoagulants in patients with non-valvular atrial fibrillation: Executive summary. Eur Heart $J$ Published Online First: 2013. doi:10.1093/eurheartj/eht134

Fanola CL, Ruff CT, Murphy SA, et al. Efficacy and safety of edoxaban in patients with active malignancy and atrial fibrillation: Analysis of the engage AF-TIMI 48 trial. J Am Heart Assoc Published Online First: 2018. doi:10.1161/JAHA.118.008987

Steffel J, Verhamme P, Potpara T, et al. The 2018 European Heart Rhythm Association Practical Guide on the use of non-vitamin K antagonist oral anticoagulants in patients with atrial fibrillation. Eur Heart J 2018;00:1-64. doi:10.1093/europace/euv309 
93 Seiffge DJ, Traenka C, Polymeris A, et al. Early start of DOAC after ischemic stroke: Risk of intracranial hemorrhage and recurrent events. Neurology 2016;87:1856-62. doi:10.1212/WNL.0000000000003283

Gioia LC, Kate M, Sivakumar L, et al. Early rivaroxaban use after cardioembolic stroke may not result in hemorrhagic transformation: A prospective magnetic resonance imaging study. Stroke 2016;47:1917-9. doi:10.1161/STROKEAHA.116.013491

Seiffge $D$, Werring $D$, Paciaroni $M$, et al. Timing of anticoagulation after recent ischaemic stroke in patients with atrial fibrillation. Lancet Neurol 2018; In press.

96 Mazya M V., Lees KR, Markus R, et al. Safety of intravenous thrombolysis for ischemic stroke in patients treated with warfarin. Ann Neurol Published Online First: 2013. doi:10.1002/ana.23924

97 Seiffge DJ, Traenka C, Polymeris AA, et al. Intravenous Thrombolysis in Patients with Stroke Taking Rivaroxaban Using Drug Specific Plasma Levels: Experience with a Standard Operation Procedure in Clinical Practice. J Stroke 2017;19:347-55. doi:10.5853/jos.2017.00395

98 Seiffge DJ, Kägi G, Michel P, et al. Rivaroxaban plasma levels in acute ischemic stroke and intracerebral hemorrhage. Ann Neurol 2018;83:451-9. doi:10.1002/ana.25165

99 Dans AL, Connolly SJ, Wallentin L, et al. Concomitant use of antiplatelet therapy with dabigatran or warfarin in the randomized evaluation of long-term anticoagulation therapy (RE-LY) trial. Circulation 2013;127:634-40. doi:10.1161/CIRCULATIONAHA.112.115386

100 Flaker GC, Gruber M, Connolly SJ, et al. Risks and benefits of combining aspirin with anticoagulant therapy in patients with atrial fibrillation: An exploratory analysis of stroke prevention using an oral thrombin inhibitor in atrial fibrillation (SPORTIF) trials. Am Heart J 2006;152:967-73. doi:10.1016/j.ahj.2006.06.024

101 Anderson CS, Heeley E, Huang Y, et al. Rapid Blood-Pressure Lowering in Patients with Acute Intracerebral Hemorrhage. N Engl J Med 2013;368:2355-65. doi:10.1056/NEJMoa1214609

102 Steiner T, Poli S, Griebe M, et al. Fresh frozen plasma versus prothrombin complex concentrate in patients with intracranial haemorrhage related to vitamin $\mathrm{K}$ antagonists ( INCH ): a randomised trial. Lancet Neurol 2016;15:566-73. doi:10.1016/S1474-4422(16)00110-1

103 Pollack C V., Reilly PA, van Ryn J, et al. Idarucizumab for Dabigatran Reversal - Full Cohort Analysis. N Engl J Med 2017;377:431-41. doi:10.1056/NEJMoa1707278 
104 Connolly SJ, Milling TJ, Eikelboom JW, et al. Andexanet Alfa for Acute Major Bleeding Associated with Factor Xa Inhibitors. N Engl J Med 2016;375:1131-41. doi:10.1056/NEJMoa1607887

105 Tsivgoulis G, Wilson D, Katsanos AH, et al. Neuroimaging and clinical outcomes of oral anticoagulant associated ICH. Ann Neurol 2018;:1-31. doi:10.1002/ana.25342

106 Murthy SB, Gupta A, Merkler AE, et al. Restarting Anticoagulant Therapy after Intracranial Hemorrhage: A Systematic Review and Meta-Analysis. Stroke 2017;48:1594-600. doi:10.1161/STROKEAHA.116.016327

107 Pennlert J, Overholser R, Asplund K, et al. Optimal Timing of Anticoagulant Treatment after Intracerebral Hemorrhage in Patients with Atrial Fibrillation. Stroke 2017;48:314-20. doi:10.1161/STROKEAHA.116.014643

108 Poon MTC, Fonville AF, Al-Shahi Salman R. Long-term prognosis after intracerebral haemorrhage: systematic review and meta-analysis. J Neurol Neurosurg Psychiatry 2014;85:660-7. doi:10.1136/jnnp-2013-306476

109 Wilson D, Ambler G, Shakeshaft C, et al. Cerebral microbleeds and intracranial haemorrhage risk in patients anticoagulated for atrial fibrillation after acute ischaemic stroke or transient ischaemic attack (CROMIS-2): a multicentre observational cohort study. Lancet Neurol 2018;17:539-47. doi:10.1016/S1474-4422(18)30145-5

110 Blackshear JL, Odell JA. Appendage obliteration to reduce stroke in cardiac surgical patients with atrial fibrillation. Ann. Thorac. Surg. 1996;61:755-9. doi:10.1016/0003-4975(95)00887-X

111 Holmes DR, Reddy VY, Turi ZG, et al. Percutaneous closure of the left atrial appendage versus warfarin therapy for prevention of stroke in patients with atrial fibrillation: a randomised non-inferiority trial. Lancet 2009;374:534-42. doi:10.1016/S0140-6736(09)61343-X

112 Holmes DR, Kar S, Price MJ, et al. Prospective randomized evaluation of the watchman left atrial appendage closure device in patients with atrial fibrillation versus long-term warfarin therapy: The PREVAIL trial. J Am Coll Cardiol 2014;64:1-12. doi:10.1016/j.jacc.2014.04.029

113 Reddy VY, Doshi SK, Kar S, et al. 5-Year Outcomes After Left Atrial Appendage Closure: From the PREVAIL and PROTECT AF Trials. J Am Coll Cardiol 2017;70:2964-75. doi:10.1016/j.jacc.2017.10.021

114 Ferlini M, Rossini R. Left atrial appendage closure: Six reasons why I wouldn't choose a percutaneous closure for my appendage. Int J Cardiol 2018;251:42-4. 
doi:10.1016/j.ijcard.2017.09.015

115 Reddy VY, Möbius-Winkler S, Miller MA, et al. Left atrial appendage closure with the watchman device in patients with a contraindication for oral anticoagulation: The ASAP study (ASA plavix feasibility study with watchman left atrial appendage closure technology). J Am Coll Cardiol 2013;61:2551-6. doi:10.1016/j.jacc.2013.03.035

116 Horstmann S, Zugck C, Krumsdorf U, et al. Left atrial appendage occlusion in atrial fibrillation after intracranial hemorrhage. Neurology 2014;82:135-8. doi:10.1212/WNL.0000000000000022

117 Connolly SJ, Eikelboom J, Joyner C, et al. Apixaban in patients with atrial fibrillation. N Engl J Med 2011;364:806-17. doi:10.1056/NEJMoa1007432

118 Calkins H, Hindricks G, Cappato R, et al. 2017 HRS/EHRA/ECAS/APHRS/SOLAECE expert consensus statement on catheter and surgical ablation of atrial fibrillation. Eur Eur pacing, arrhythmias, Card Electrophysiol J Work groups Card pacing, arrhythmias, Card Cell Electrophysiol Eur Soc Cardiol 2018;20:e1-160. doi:10.1093/europace/eux274

119 Noseworthy PA, Kapa S, Deshmukh AJ, et al. Risk of stroke after catheter ablation versus cardioversion for atrial fibrillation: A propensity-matched study of 24,244 patients. Hear Rhythm 2015;12:1154-61. doi:10.1016/j.hrthm.2015.02.020

120 Packer DL, Lee KL, Mark DB, et al. Cather ABlation vs ANtiarrhythmic Drug Therapy in Atrial Fibrillation (CABANA) Trial Results Presentation, Heart Rhythm Society 39th Annual Scientific Sessions. 2018.https://www.cabanatrial.org/wp-content/uploads/2018/05/CABANA-TrialSlides-05092018FINAL.pdf (accessed 7 Dec 2018).

121 Hart RG, Diener HC, Coutts SB, et al. Embolic strokes of undetermined source: The case for a new clinical construct. Lancet Neurol 2014;13:429-38. doi:10.1016/S1474-4422(13)70310-7

122 Hart RG, Sharma M, Mundl H, et al. Rivaroxaban for Stroke Prevention after Embolic Stroke of Undetermined Source. N Engl J Med 2018;378:2191-201. doi:10.1056/NEJMoa1802686

123 Diener H-C, Easton JD, Granger CB, et al. Design of Randomized, Double-Blind, Evaluation in Secondary Stroke Prevention Comparing the Efficacy and Safety of the Oral Thrombin Inhibitor Dabigatran Etexilate vs. Acetylsalicylic Acid in Patients with Embolic Stroke of Undetermined Source (Re-Spect E. Int J Stroke 2015;10:1309-12. doi:10.1111/ijs.12630

124 Geisler T, Poli S, Meisner C, et al. Apixaban for treatment of embolic stroke of undetermined source (ATTICUS randomized trial): Rationale and study design. Int J Stroke 2016;12:985-90. 
125 Kamel H, Hunter M, Moon YP, et al. Electrocardiographic left atrial abnormality and risk of stroke: Northern manhattan study. Stroke Published Online First: 2015. doi:10.1161/STROKEAHA.115.009989

126 Hansen M, Sørensen R, Clausen M, et al. Risk of Bleeding With Single, Dual, or Triple Therapy With Warfarin, Aspirin, and Clopidogrel in Patients With Atrial Fibrillation. 2010;170:1433-41.

127 Lamberts M, Gislason GH, Lip GYH, et al. Antiplatelet Therapy for Stable Coronary Artery Disease in Atrial Fibrillation Patients Taking an Oral Anticoagulant: A Nationwide Cohort Study. Circulation 2014;129:1577-85. doi:10.1161/CIRCULATIONAHA.113.004834

128 Lamberts M, Lip GYH, Ruwald MH, et al. Antithrombotic treatment in patients with heart failure and associated atrial fibrillation and vascular disease: A nationwide cohort study. J Am Coll Cardiol 2014;63:2689-98. doi:10.1016/j.jacc.2014.03.039

129 Chen ST, Hellkamp AS, Becker RC, et al. Impact of polyvascular disease on patients with atrial fibrillation: Insights from ROCKET AF. Am Heart J 2018;200:102-9. doi:10.1016/j.ahj.2018.02.013

130 Hurlen M, Abdelnoor M, Smith P, et al. Warfarin, Aspirin, or Both after Myocardial Infarction. N Engl J Med 2002;347:969-74. doi:10.1056/NEJMoa020496

131 Eikelboom JW, Connolly SJ, Bosch J, et al. Rivaroxaban with or without Aspirin in Stable Cardiovascular Disease. N Engl J Med 2017;377:320-30. doi:10.1056/NEJMoa1709118 